\title{
HISTÓRIAS CRUZADAS: PAISAGEM, CULTURA E ESPAÇOS PÚBLICOS NA BARRA DA LAGOA
}

\author{
SARA DOTTA CORREA | UFSC \\ LISIANE ILHA LIBRELOTTO, DRA. | UFSC \\ SAMUEL STEINER DOS SANTOS, DR. | UFSC
}

"Foi restinga, foi areia, manguezal, floresta.

Foi parte da Lagoa da Conceição,

Mas era bonita demais para ser parte,

Então se fez tudo, Barra da Lagoa.

Barra da Lagoa, cantinho de ilha,

Conta-me a tua história,

Aquela que o canal,

As áreas verdes, o mar e o mangue,

Eram os personagens principais?

Para onde tuas trilhas levavam

Os passos que já se foram?

Você se lembra de quando tua orla

Começou a ter porta, portão, muros e grades?

Ou quando de tua beleza fizeram propriedade?"

Fragmento do poema Histórias Cruzadas Fonte: Autoral

Esse trabalho teve como objetivo elaborar uma intervenção na paisagem em um recorte do bairro e parte da orla do canal da praia da Barra da Lagoa, em Florianópolis, SC. A área total do distrito é de $4,75 \mathrm{~km} 2$, e está numa área privilegiada, incrustada entre o mar, a Lagoa da Conceição Morro da Galheta e o Parque Estadual do Rio Vermelho. O distrito é cortado pelo Canal da Barra que liga as águas da a Lagoa da Conceição com as águas do oceano. A localidade é constituída por habitações, bares, restaurantes, mercados, pousadas e hotéis em grande parte do território, além dos ambientes naturais, praia, canal d'água, piscinas naturais, grandes rochas, montanhas, sítios arqueológicos e áreas de preservação permanente. Rico em tradições culturais e histórias pra contar, esse cenário sofreu modificações de grande impacto, tanto na paisagem, na fauna e flora, no caráter da ocupação, como na economia e na sociedade ao longo dos anos.
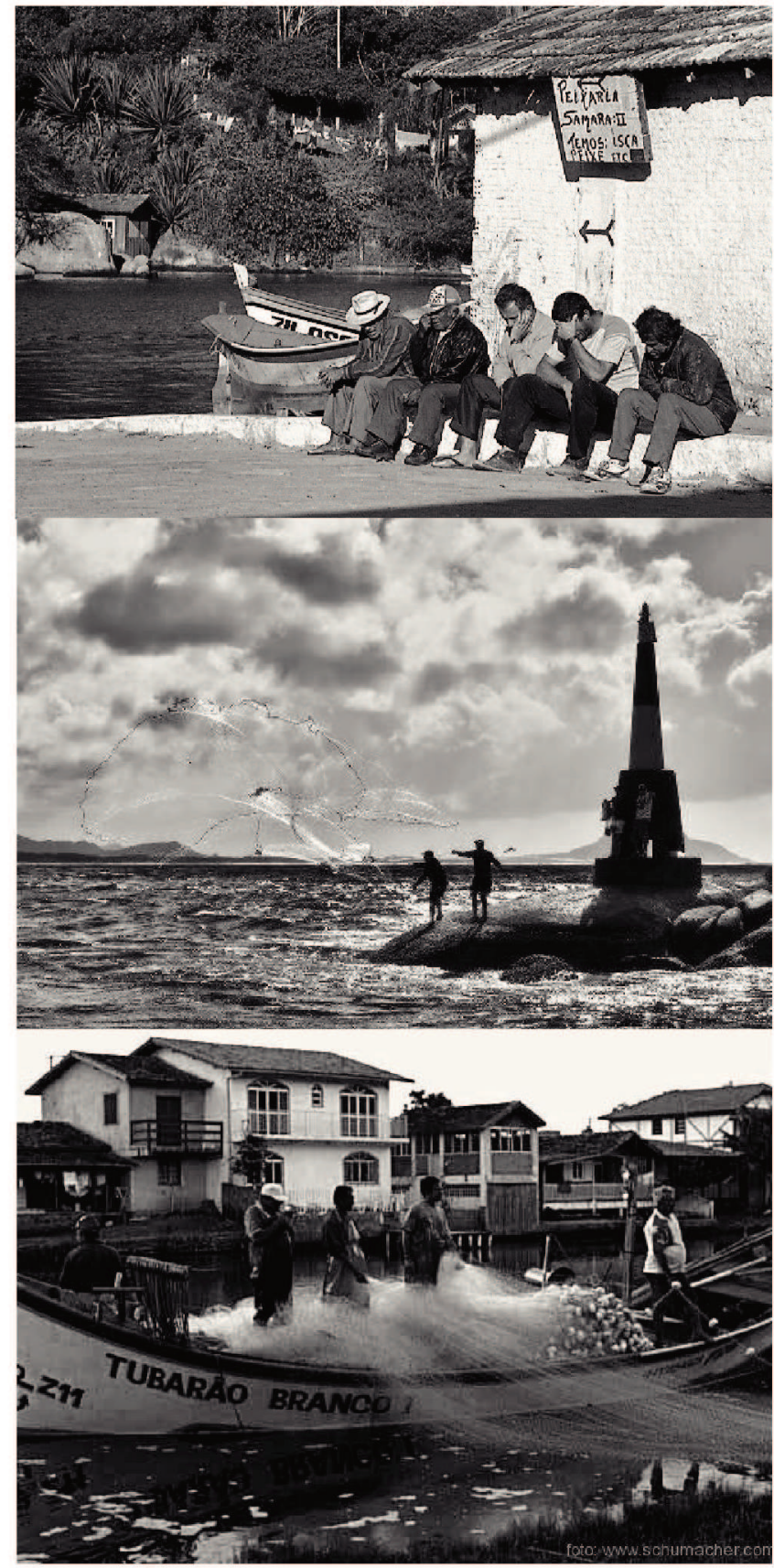

Fotos: AndréPaiva 
Dessa forma, buscando um estado de resiliência, resgatando a cultura através da recuperação de memórias e do fortalecimento de laços entre locais de braços dados com a nova economia gerada pelo turismo, essa intervenção se concentrou na região conhecida como "centrinho" ou próximo ao "estacionamento" do bairro. As ilustrações de alguns entrevistados questionados acerca da sua "imagem da Barra da Lagoa' e elementos de destaque na paisagem podem ser observadas nas três figuras abaixo.
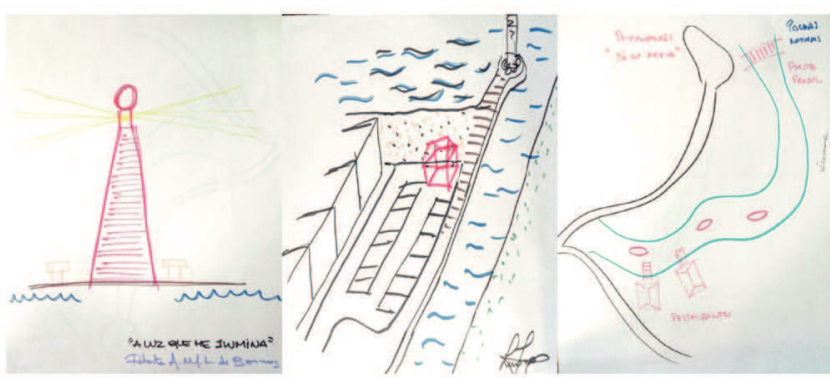

Fonte: Autoral

O projeto deu ênfase a orla e novos espaços públicos que foram reconstituídos depois do levantamento de dados (Mapa 1), entrevistas, conversas com representantes do Centro Comunitário da Barra da Lagoa, registros fotográficos antigos concedidos pela comunidade. A partir daí foi elaborada a rela-

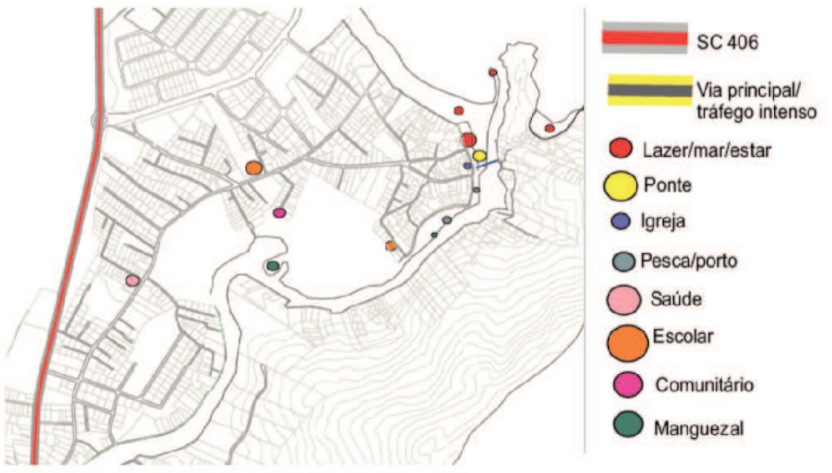

Mapa 1: Principais equipamentos urbanos do bairro Fonte: Autoral

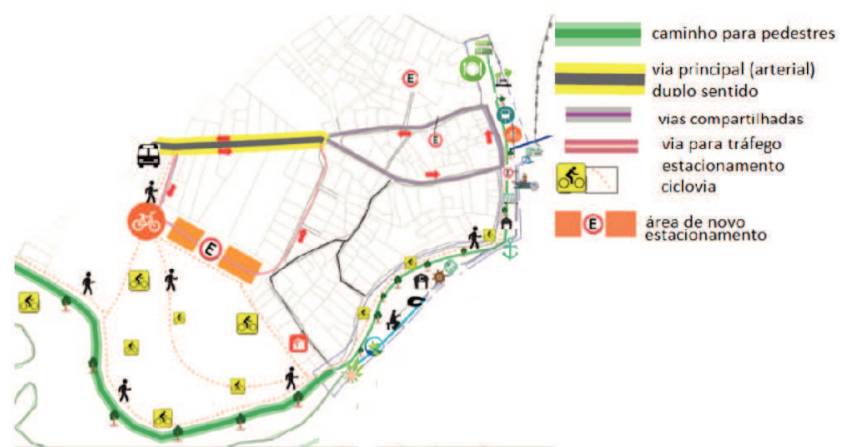

Mapa 2: Área de intervenção em escala de bairro Fonte: Autoral

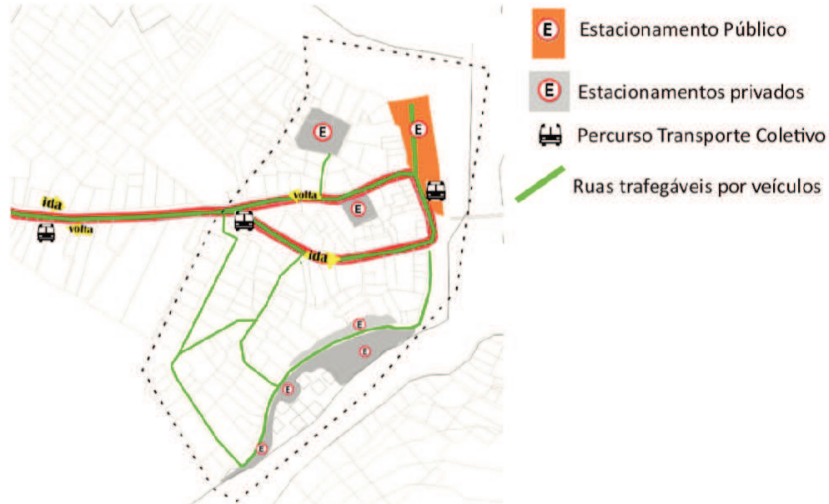

Mapa 3: Área de intervençăo em escala de bairro Fonte: Autoral

Assim, a proposta em escala de bairro procurou costurar os principais equipamentos urbanos do bairro (Mapa 2) através da implementação de novos percursos agradáveis a travessia e priorizando o pedestre, o meio ambiente, a cultura local e o turismo de contemplação (Mapa 3).

A área contornada no mapa abaixo (Mapa 4) foi o objeto de aplicação da intervenção paisagística haja vista que no local se concentram várias condicionantes ambientais como orla marítima, vegetação degradada, declive acentuado, remanescente de mata atlântica, cursos da água, além de outras questões, dentre as quais se destacando, principalmente, marina em situação precária, porto e área de lazer e estar sendo ocupadas como estacionamento, falta de áreas verdes/ esporte e falta de infraestrutura para a prática da pesca (Mapa 5), considerando que a Barra da Lagoa é a maior colônia de pescadores da ilha de Florianópolis, denominada Colônia Z11.

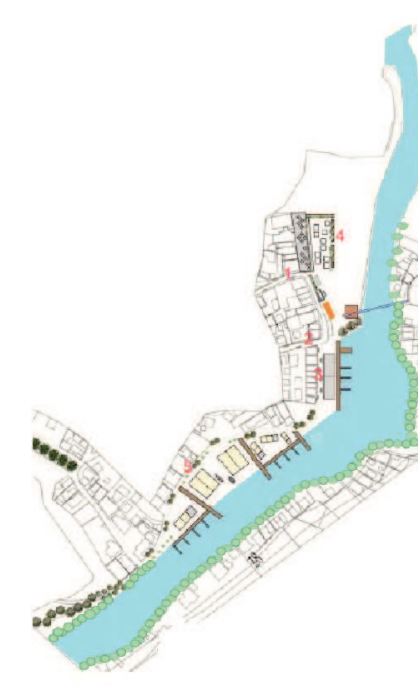

Mapa 4: Atual Fonte: Google Earth 2018

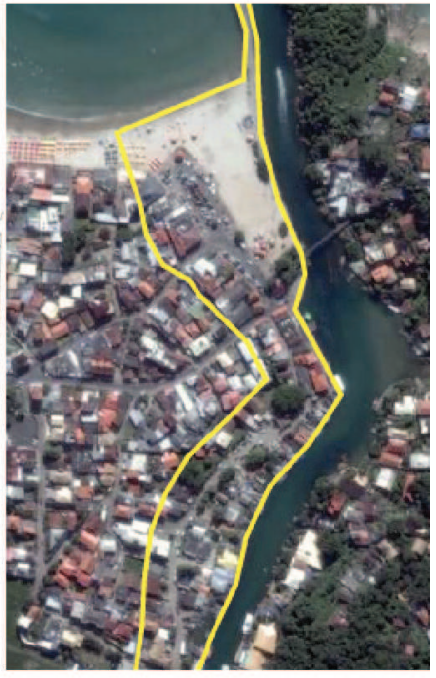

Mapa 5: De implantaçăo proposta Fonte: Autoral 
Assim, os detalhes dos ambientes criados para a implantação proposta são demonstrados nas imagens abaixo:

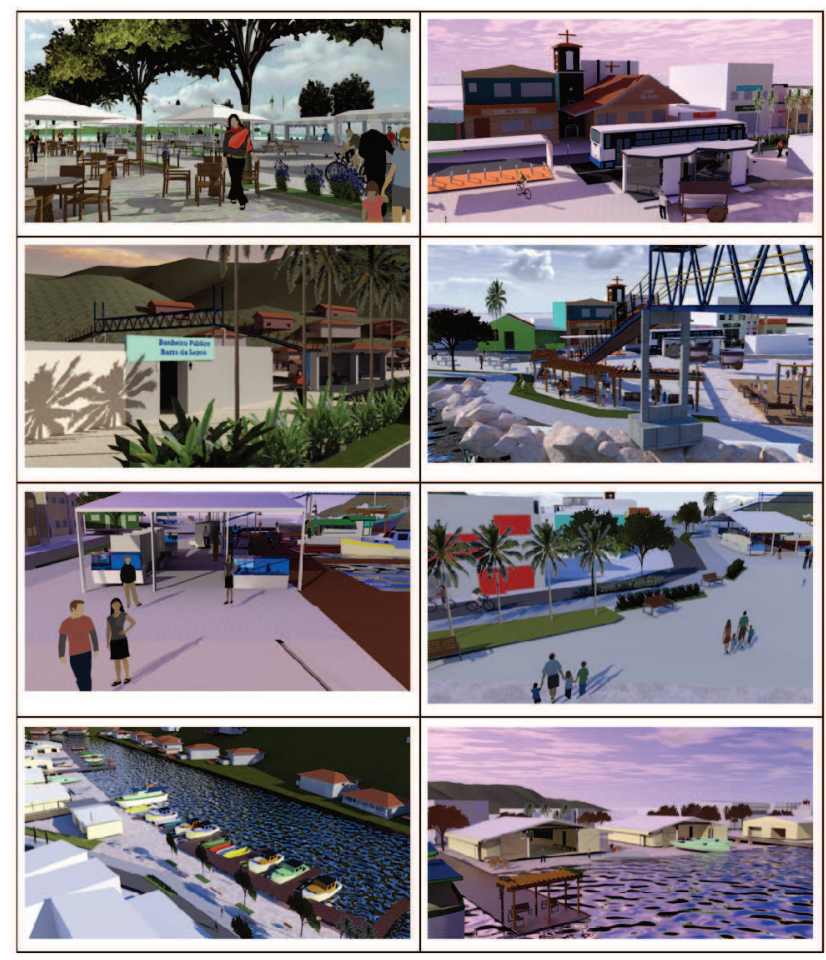

